\title{
Reading Comprehension Application (RCA) On Smartphone Usage In Classroom
}

\author{
Endah $^{1}$, Dyah Sunggingwati ${ }^{2}$, Effendi Limbong ${ }^{3}$ \\ Department of English Education, Faculty of Teacher Training and Education, Mulawarman University, Indonesia \\ endah@gmail.com, sunggingwati@gmail.com, limbong_efflin@yahoo.com
}

\begin{abstract}
The primary objectives of this study were (1) to find out learners' reading comprehension achievement after learning English using Reading Comprehension Application (RCA) on smart phone, (2) to find out if there is any significant effect of RCA on Smartphone usage in learning English. The findings revealed that learners gain higher achievement on their post-test (67.81) score rather than on the pre-test score (62.65). Furthermore, there was significant difference of pre-test and post-test mean score (Sig. level $0.001<0.05$ ). The results constituted that there was improvement on learner's reading comprehension achievement based on the pre-test and post-test findings presentation after learning English using Reading Comprehension Application (RCA) on smart phone.
\end{abstract}

Keywords-Reading comprehension; Reading Comprehension Application (RCA); Smart phone

\section{INTRODUCTION}

As reading is a complex process, readers need to understand certain texts by constructing and extracting text's meaning. Comprehension process involves recalling information from text, extracting themes, engaging in higher order thinking skills, constructing a mental picture of text, and understanding text structure which generate challenges. Therefore, the importance of constructing meaning has led to a conclusion that 'the most important thing in reading is comprehension' [1].

In the 21 st century, the definition of literacy has expanded from traditional notions of reading and writing to include the learners' ability to learn, comprehend, and interact with technology [2]. Therefore, experts try to invent solutions to help poor comprehenders. One of the most widely used ways is by using technology as teaching and learning tools such as eBook, computer games, and various applications which can improve learners' reading achievement.

Research showed that technology provided more teaching resources ad authentic materials for learners' experience and learning motivation enhancement. Electronic chatting; games, e-pan pals and podcasts could be interesting features for language learners. Mobile dictionaries use offers efficient time and assists language learners to acquire vocabulary and check verb conjugations easily [3]. It also provides good features included in it such as visual media (images, graphics), audio media (pronunciation), multimedia, and searching. It can also be the reason of better learning when learners use mobile dictionaries $[4,5]$.

Nowadays, smart phone is much more sophisticated than the old model and free from the constraints of location specificity, apart from the basic capability of communication. There are more and more features have been added, such as full color screen, texting function, mp3 function, and embedded camera [6].

The latest smart phone models are just like mini-computer and provides a lot of capabilities such as a video camera, telephone, GPS, movie player, games, eBooks, e-mail, and the facilitation of internet access, music MP3, short messages, and the ability to download various apps designed for different purposes [7, 8]. Social networks applications, such as Facebook, Twitter, Line, WhatsApp, and Blackberry Messenger on learners' smart phones allow learners to form groups in order to distribute and share their knowledge easily, resulting in more successful collaborative learning [9, 10]. Smart phone is not only as an integral part of how knowledge and its discourse transform, it also creates new ways of accessing and sharing knowledge [10].

Recently middle and higher education in developed and developing countries are now trying to adopt the use of smart phones in the learning process from different perspectives and teaching methods [11]

Smart phones provide learning and training support for learners through their capabilities, which include the enabling of quick content delivery, enhanced support time in projectbased group work, a higher level of learner engagement in learning-related activities within a multitude of diverse physical locations, and the enhanced availability and accessibility of information $[12,13]$.

Such applications are not only providing better comprehension but also improving communication. Using each of the above-mentioned applications on smart phone is also relevant and may potentially provide opportunities to learn English as the respondents listened to radio programs and read English books and articles [14].

[15] investigated the effect of electronic storybook on struggling fourth-graders' reading comprehension to seek which features and types of storybook presentations are more effective than other for struggling readers. Using experimental 
research design, findings revealed that learners who read using storybook with animation acquired the highest score followed by learners who read using storybook without animation. In addition, the lowest score was acquired by learners who read the traditional print storybook. E-storybook with animation has static illustration and animated illustration which help reader to enhance comprehension, to make inferences, to understand theme and resolution. E-storybook has interactivity, rich visual support and animation, design quality of on-screen, selfdirection, self-selected book, and novelty effect. Thus, estorybook is interesting, more effective to activate background knowledge, deeper processing of information, and support for independent reader.

Research on reading engagement and comprehension of children as they read electronic books using a mixed method design (experimental and survey) was conducted. The comprehension tests and the surveys revealed that the format in which children read the material is not an important indicator for the research. The eBook format did not significantly increase comprehension, enjoyment, or engagement. It was clearly indicated that learners prefer having a choice of reading material and that the format was not as central to reading engagement as a connection with the story's characters and setting [16].

A qualitative research was undertaken about using electronic books as a teaching tool for beginning readers from four perspectives: the researcher as an observer, the grade 1 learner participants, their teachers, and their parents. The research revealed that the participants showed the enjoyment in engaging with online reading program, since the online books were different with the printed ones, and completed with multimedia, such as animation and audio. Not only the five learners with high level reading skills, but also the other three gave positive attitude over online reading experience. They were excited, motivated, interested, willing to read online books not only during the research, but also at home [17].

The effectiveness of eBooks using of mobile tablet-PC iPad Mini in online ERP (Extensive Reading Program) for 84 learners from two 10th-grade classes with the same English teacher in a senior high school in northern Taiwan, English learners. The experimental research showed that learners who read using mobile PC out performed learners who read using $\mathrm{PC}$ as learners with mobile $\mathrm{PC}$ spent more time, read more books, and took more tests on the online ERP than learners with PC did. The reading skills tests showed that learners with mobile PC outscored learners with PC in reading achievement. The mobile tablet PC helped out learners gained English reading skills more effectively than the PC did in online ERP. Learners gave greater appreciation of the online ERP on mobile tablet than the PC. They found the reading device and program more useful and more satisfying [18].

The effect of electronic books on enhancing emergent literacy skills than traditional printed books of pre-school children was investigated. Using experimental and comparison design, the findings showed, E-book were so novel, better vehicle to learn, interesting and attractive, and provided chance to engage with interactive features. E-book helped learners improved areas in emergent literacy developments [14].
The type of application used for the present research is not much different from eBooks in general. Which makes Reading Comprehension Application (RCA, hereafter) different from the eBook in general is that this application includes reading comprehension questions that can be done immediately after readers finish reading the stories available and it is used via smart phone. This application is also equipped with the correction section that will appear once readers finish selecting the answer for the questions given, if readers chose the wrong answer, RCA will provide the correct answer. After the readers finish working the whole questions, the final screen will present the final score to show the number of correct and incorrect answers has chosen.

This application is an offline app. Internet connection is needed to download the application only. Thus, users can use this application although there is no internet connection. In addition, this application is not used on PC, tablet or laptop; it is used on smart phones.

\section{METHODOLOGY}

This study employed pre-experimental design with 31 learners as the participants (including 12 males and 19 females). They were from one science program EFL classroom on the first year in SMA Negeri 5 Samarinda. Reading Ultimate Application was chosen and Smartphone was used as the media. The data were collected by conducting pre-test and post-test. It was also intended to see if there was any significant effect from the treatment given. The researchers used achievement test since it was the most suitable instrument to use in this research because we wanted to measure learners reading comprehension skill by doing a test.

The instrument of this research was reading comprehension test as the pre-test and the post-test, taken from reading comprehension application. The application was Reading Ultimate Application for grade 3, 4 and 5. The free version of this application could be downloaded from play store. The application provides 12 original fiction and non-fiction stories.

The test form was a reading passage, followed by some multiple choice questions related to the reading passage. The types of the texts were divided into two major kind of texts, fiction and nonfiction stories for children. We used the fiction and non-fiction text since the type of the text was accord with the syllabus used at the school. The text and questions were taken from the "Reading Ultimate" application. Both pre-test and post-test were done by using paper or printed version.

There were six passages used as the instrument of the treatment taken from the fiction stories and the non-fiction stories. Twelve until thirteen questions followed each passage. The questions were in multiple choices form and standardized questions since it was aligned with Common Core State Standards (CCSS). However, the researchers kept doing the did try-out to provide a good test to ensure the validity and reliability of the test. Furthermore, item analysis was used for the try out questions. First, the test was tried out, and then after data processing, the questions that did not comply with the requirement were eliminated. 
The data were collected after six meetings in the classroom. First, the researchers tried out the test in class X IPA1. After that, we analyzed the test to check the validity and reliability of the test, and then selected 38 items to be used in the real test. The selected 38 items would be used as the pre and post-test items.

The pre-test was given before the treatment. After giving the pre-test, the researchers gave learners the materials for six meetings and continued by giving the learners the post-test. The details of the teaching process could be seen in the teaching procedures as follows.

\section{Teaching Procedure}

For the teaching procedures, there were six meetings. During the teaching and learning process, learners used RCA from their Smartphone for learning activities, except for the pre-test and the post test. Besides RCA, learners also used search engine and mobile dictionary. Both text type from the $\mathrm{RCA}$; fiction and non-fiction texts with the same procedures, was taught.

On the first meeting, the learners were taught the material of text types in the application and did exercise by using the RCA on smart phone. The second meeting, the researchers gave learners the materials about reading strategy and how to implement the strategy during reading. Exercise for learners using the RCA on smart phone was also completed. Next, the learners were required to do exercise autonomously at home using the application and the results of their exercise were discussed in the third meeting focusing on the difficulties they faced during doing the exercise at home and did more exercises. Reviewing all the materials given in the first and second meeeting was included. Similar procedures were employed for the fourth, fifth and sixth meeting but with different text type; non-fiction one. The time for each treatment was approximately 40 minutes.

\section{RESULTS AND DISCUSSION}

\section{A. The findings of pretest and posttest}

The pre-test score of the sample was presented in Table 1. From the table 3.1 , it could be seen that the mean score was 62.65 and the post-test mean score was 67.81. There was an increasing of mean score after the treatment was given.

Researcher then grouped the pre-test and post-test score data into the frequency distribution to categorize the scores. It also aimed to summarize the pre-test and post-test score data, thus it would be easier to read the data.
TABLE I. FREQUENCY DISTRIBUTION FOR CATEGORIZING THE PRETEST AND POSTTEST SCORES

\begin{tabular}{|c|c|c|c|c|}
\hline \multirow{2}{*}{$\begin{array}{c}\text { Quantitative } \\
\text { Score }\end{array}$} & Qualification & Categorization & $\begin{array}{c}\text { Pre- } \\
\text { test }\end{array}$ & $\begin{array}{c}\text { Post } \\
\text {-test }\end{array}$ \\
\hline $80-100$ & A & Excellent & 1 & 4 \\
\hline $70-79$ & B & Good & 6 & 11 \\
\hline $60-69$ & C & Fair & 14 & 8 \\
\hline $50-59$ & D & Poor & 8 & 7 \\
\hline $49-$-under & E & Very Poor & 2 & 1 \\
\hline \multicolumn{3}{|c|}{ Total Frequency $(\mathrm{N})$} & 31 & 31 \\
\hline \multicolumn{4}{|c}{} \\
\hline
\end{tabular}

To provide more clear data comprehension, researcher also presented the data in pie chart as follow.

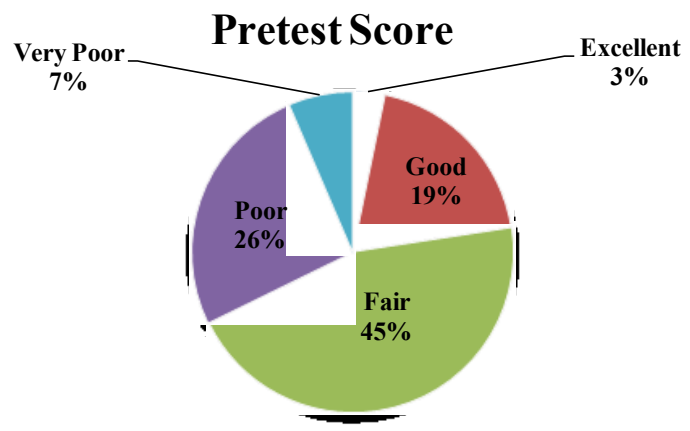

Fig. 1. Percentage of Learners' Pre Test

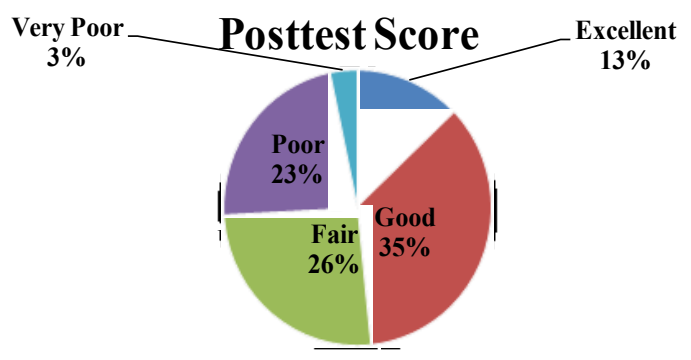

Fig. 2. Percentage of Learners' Post Test

The pie charts compare learners' pre-test and post-test score categorization in percentage terms. From the pre-test chart, the largest category was learners with Fair score, $45 \%$. The next largest category was Poor, accounting for $26 \%$. The remaining category was Good, amounting to $19 \%$ followed by Very Poor $7 \%$ and with tiny fraction of learners with Excellent category was only $3 \%$, it was only one learner who achieved highest score based on the categorizing table.

Six weeks later after the treatment given, the number of learners with Excellent category had risen to $13 \%$, this was an increase of $10 \%$ compared with pre-test. Much of the increase in Excellent category could be explained by the decrease in Fair from $45 \%$ into 35\%, Poor from $26 \%$ into 23\% and Very Poor category, which had dropped from $7 \%$ to $3 \%$. 


\section{B. The Finding of Mean Score Comparison}

Data analysis for the second research question began with comparing the pre-test and post-test mean score. Paired t-test was used to compare the mean score of pre-test and post-test, to find out if there was any significant effect of RCA on smart phone usage in classroom toward learners' academic achievement in English subject particularly their reading comprehension, and also to test the hypotheses. Researchers analyzed the mean score comparison using SPSS 21 software. Beforehand, the hypotheses and decision making process were presented as follows:

$\mathrm{H}_{\mathrm{o}}$ : There is no significant difference mean score between pretest and post-test after learners are taught by using smart phone and RCA.

$\mathrm{H}_{\mathrm{a}}$ : There is significant difference mean score between pretest and post-test after learners are taught by using smart phone and RCA

Decision making from the finding:

$$
\begin{aligned}
& \text { If } \mathrm{t}_{\text {value }}<t_{\text {table }\left(n-1 ; \frac{\alpha}{2}\right)} \text { or } \operatorname{sig}_{\text {value }}<\alpha ; \mathrm{H}_{\mathrm{o}} \text { is rejected. } \\
& \text { If } \mathrm{t}_{\text {value }}>t_{\text {table }\left(n-1 ; \frac{\alpha}{2}\right)} \text { or } \operatorname{sig}_{\text {value }}>\alpha ; \mathrm{H}_{\mathrm{o}} \text { is accepted. }
\end{aligned}
$$

TABLE II. FINDING OF PAIRED T-TEST:

\begin{tabular}{|c|c|}
\hline Results & Value \\
\hline t-value & -3.780 \\
\hline Sig. (2- tailed) & 0.001 \\
\hline
\end{tabular}

\section{Decision making}

Based on the computation using software SPSS 21 the finding of tvalue was -3.780 . Meanwhile, the value of ttable with level of significance $\alpha=0.05$ and degree of freedom (df) $=30$ was 2.042 . It showed that tvalue was lower than ttable ($3.780<2.042)$ which meant Ho was rejected. The result was supported by the result of Sigvalue which was 0.001 with the significant level $\alpha=0.05$. It showed that Sig. value was lower than Sig. level $(0.001<0.05)$ which meant Ho was rejected. It could be concluded that there was significant difference of pretest and post-test mean score.

It means learners who had been taught by using RCA on smart phone had greater achievement on their post-test score than the pre-test score. Thus, teaching English by using RCA on smart phone gave a positive effect on learners' English achievement particularly their reading comprehension based on their reading comprehension test score.

This research found that the using of RCA on smart phone improved and supported reading comprehension of learners. Their reading comprehension achievement after learning English using smart phone and RCA increased significantly.

The main point was regarding the first and second research questions. The reading comprehension pre- and post-tests were carried out to discover whether the treatment was effective in improving learners' reading ability. The paired t-test computation finding from the SPSS 21 data analysis revealed significant difference of pre-test and post-test mean score. Therefore, teaching English using RCA on smart phone gave positive effect on learners' English achievement particularly their reading comprehension. These findings were consistent with previous research done by $[14,15,18]$, the using of eBooks and smart phone could enhance learner's language achievement. EBooks and smart phone as technology could be beneficial learning tools. The features embedded within electronic storybooks contribute to children's reading development, further research also revealed students' experiences with, attitudes toward, and their motivation for reading these digital texts in the early primary grades are warranted. It provided more teaching resources and brought new and different learning experience to learners' world.

\section{CONCLUSION}

The participants practiced this activity for about 6 meetings. They then took the pre- and post-tests. There was an overall improvement in English reading comprehension performance in the post-test. The participants expressed positive response to the treatment. As most participants in the research did not have opportunities to download the application and used it individually, they appreciated being able to use the application offered by doing assignment in group works or pair works.

The findings of the present research suggest that the use of RCA on smart phone could provide a useful context for obtaining better achievement on the reading comprehension. One of the advantages of RCA on smart phone is that it provides opportunities to use smart phone as more beneficial tool for learning English rather than just for entertaining purpose. EFL English teacher, particularly in Samarinda can use RCA on smart phone as a helpful teaching tool moreover if there will be further development whether for the application, device, or the teaching method. However, there are some limitations that need to be considered in using RCA on smart phone.

\section{REFERENCES}

[1] C. C. Block, L. B. Gambrell, and M. Pressley. (2002). Improving comprehension instruction: Rethinking research, theory, and classroom practice.

[2] M. T. de Jong and A. Bus, "Quality of book-reading matters for emergent readers: An experiment with the same book in a regular or electronic format," Journal of Educational Psychology, vol. 94(1), pp. $145-155,2002$.

[3] A. Kukulska-Hulme, "Language learning defined by time and place: A framework for next generation designs," Learner autonomy and Mobile Assisted Language Learning. Innovation and leadership in English language teaching, vol. 6, pp. 1-13, 2012.

[4] S. Joseph and M. Uther, "Mobile devices for language learning: Multimedia approach," Research and Practice in Technology Enhanced Learning, vol. 4, pp. 7-32, 2009.

[5] M. Rahimi and S. S. Miri, "The impact of mobile dictionary use on language learning," Procedia-Social and Behavioral Sciences, vol. 98, pp. 1469-1474, 2014.

[6] H. Lacohée, N. Wakeford, and I. Pearson, "A social history of the mobile telephone with a view of its future," BT Technology Journal, vol. 21(3), pp. 203-211, 2003.

[7] M. Ally. (2009). Mobile learning: Transforming the delivery of education and training. 
[8] M. Sharples, I. Arnedillo-Sánchez, M. Milrad, and G. Vavoula, "Mobile learning: Small devices, big issues," Technology-enhanced learning, vol. Part IV, pp. 233- 249, 2009.

[9] H. L. Dangel and C. X. Wang, "Student response systems in higher education: Moving beyond linear teaching and surface learning," Journal of Educational Technology Development and Exchange, vol. 1(1), pp. 93-104, 2008.

[10] L. H. Wong and C. K. Looi, "What seams do we remove in mobileassisted seamless learning? A critical review of the literature," Computers \& Education, vol. 57(4), pp. 2364-2381, 2011.

[11] L. Johnson, S. Adams Becker, V. Estrada, and A. Freeman. (2014). NMC horizon report: 2014 higher education edition.

[12] G. Clough, A. C. Jones, P. McAndrew, and E. Scanlon, "Informal learning with PDAs and smart phones," Journal of Computer Assisted Learning, vol. 24(1), pp. 359-371, 2007.

[13] H. Falaki, R. Mahajan, S. Kandula, D. Lymberopoulos, R. Govindan, and D. Estrin, "Diversity in smartphone usage," in Proceedings of the 8th international conference on Mobile systems, applications, and services, 2010, pp. 179-194.

[14] F. M. Ihmeideh, "The effect of electronic books on enhancing emergent literacy skills of pre-school children," Computer and Education, vol. 79, pp. 40-48, 2014.

[15] I. Seyit, "The effect of electronic storybook on struggling fourthgraders' reading comprehension," The Turkish Online Journal of Educational Technology, vol. 9 (4), pp. 140-155, 2010.

[16] T. Jones and C. Brown, "Reading engagement: A comparison between e-books and traditional print books in an elementary classroom," International Journal of Instruction, vol. 4 (2), pp. 5-22, 2011.

[17] K. Ciampa, "Reading in the digital age: using electronic books as a teaching tool for beginning readers," Canadian Journal of Learning and Technology, vol. 38, pp. 1-26, 2012.

[18] C.-C. Lin, "Learning reading in a mobile-assisted extensive reading program," Computers and Education, vol. 78, pp. 48-59, 2014. 